\title{
First inventory of the sandfly fauna (Diptera: Psychodidae, Phlebotominae) in the municipality of Juiz de Fora, State of Minas Gerais, Brazil
}

\author{
Izabella de Oliveira Pinheiro ${ }^{[1]}$, Milton Ferreira de Castro ${ }^{[1]}$, Murilo Gonçalves ${ }^{[1]}$, \\ Adilson da Costa Lima ${ }^{[1]}$, Glênia Maria de Magalhães Campos ${ }^{[1]}$, \\ Adalberto Mitterofhe ${ }^{[1]}$, Ricardo José de Paula Souza e Guimarães ${ }^{[2]}$, \\ José Dilermando Andrade Filho ${ }^{[3]}$ and Elaine Soares Coimbra ${ }^{[4]}$
}

[1]. Núcleo de Vigilância Epidemiológica, Ambiental e Saúde do Trabalhador, Superintendência Regional de Saúde, Secretaria de Estado da Saúde de Minas Gerais, Juiz de Fora, MG. [2]. Laboratório de Geoprocessamento, Instituto Evandro Chagas, Ananindeua, PA. [3]. Laboratório de Leishmanioses, Centro de Referência Nacional e Internacional para Flebotomíneos, Centro de Pesquisas René Rachou, Fundação Oswaldo Cruz. Belo Horizonte, MG. [4]. Departamento de Parasitologia, Microbiologia e Imunologia, Instituto de Ciências Biológicas, Universidade Federal de Juiz de Fora, Juiz de Fora, MG.

\begin{abstract}
Introduction: This study aimed to inventory the phlebotomine sandfly fauna present in the urban area of Juiz de Fora, with an emphasis on the genus Lutzomyia. Methods: Capture was performed from March to September 2012, using HP light traps placed at peridomestic sites, in a municipal kennel and a forest biome. Results: A total of 133 specimens were captured, representing eight species of the genus Lutzomyia. Lutzomyia pascalei was the most prevalent species. Conclusions: This research provides an inventory and description of the spatial locations of the phlebotomine sandfly fauna of Juiz de Fora.
\end{abstract}

Keywords: Lutzomyia. Juiz de Fora. Phlebotomine sandfly fauna.

Popularly known as mosquito-palha, birigui, cangalhinha, tatuquira, asa dura, asa branca or anjinho in Brazil, phlebotomine sandflies (Diptera: Psychodidae) are small insects of great importance in the epidemiology of various diseases, including the leishmaniases, in animals and humans ${ }^{1}$. Between 1907 and 1940, a total of 33 phlebotomine species were identified in the Americas. Since then, interest in these insects has increased that number dramatically, and approximately 400 new species and subspecies have been described ${ }^{1}$. Among these, Lutzomyia longipalpis is considered particularly important as the main vector of visceral leishmaniasis. Perfectly adapted to the urban environment, it can also be widely found in forest, transitional and cerrado biomes, reflecting its wide variety of suitable habitats and eclectic alimentary preferences ${ }^{2}$.

The municipality of Juiz de Fora $\left(21^{\circ} 41^{\prime} 20^{\prime \prime} \mathrm{S} / 43^{\circ} 20^{\prime} 40^{\prime \prime} \mathrm{W}\right)$ is situated in southeastern Minas Gerais, $283 \mathrm{~km}$ from the State capital, Belo Horizonte, and canine visceral leishmaniasis is considered endemic in this city ${ }^{3}$. Juiz de Fora has a humid subtropical climate, a mean annual temperature ranging from $15^{\circ} \mathrm{C}$ to $24^{\circ} \mathrm{C}$ and an average annual humidity of $80 \%$. Annual

\footnotetext{
Address to: Dr ${ }^{\mathrm{a}}$ Elaine Soares Coimbra. Dept ${ }^{\circ}$ de Parasitologia, Microbiologia e Imunologia/ICB/UFJF. Rua José Lourenço Kelmer s/n, Campus Universitário, Bairro Martelos, 36036-900 Juiz de Fora, MG, Brasil.

Phone: 5532 2102-3219; Fax: 5532 2102-3214

e-mail: elaine.coimbra@ufjf.edu.br

Received 29 November 2012

Accepted 7 March 2013
}

rainfall $^{4}$ varies between 1,300 and $1,500 \mathrm{~mm}$. The urban area includes several remaining areas of Atlantic rainforest. In 2008, the first cases of autochthonous canine visceral leishmaniasis were diagnosed by the Secretaria Municipal de Saúde of Juiz de Fora. However, no research on the local sandfly fauna has been conducted.

The entomological sampling was performed from March to September 2012, during 39 overnight monitoring events held in twelve neighborhoods of the eastern region of the city (Alto Grajaú, Linhares, Nossa Senhora de Lourdes, Parque Burnier/JK, Progresso, Santa Rita, Santo Antônio, São Benedito, São Bernardo, São Dimas, Tiguera and Vila Ideal). With the exception of the São Benedito neighborhood, in which both a peridomestic environment and forest biome site were investigated, one HP light trap ${ }^{5}$ was set in a peridomestic site for each household surveyed. One point of capture was also placed at the municipal kennel. In total, thirteen traps were installed, with attention given to the presence of bird and/or mammal shelters as well as of banana trees, organic matter accumulation in the soil, humidity, shade and vegetation. The traps were set from $5 \mathrm{pm}$ to $8 \mathrm{am}$ for three consecutive nights of two weeks per month (except for July, during which the collections were performed in just one week). After screening, the captured sandflies were mounted on slides. The taxonomic identification was conducted according to Young \& Duncan ${ }^{6}$. Samples were sent to the Centro de Pesquisas René Rachou, Fundação Oswaldo Cruz/ Belo Horizonte to confirm the identities. The slides were stored in the permanent collection of the Laboratório de Entomologia, Superintendência Regional de Saúde/Juiz Fora. 
The locations were georeferenced using a Global Positioning System (GPS), Garmin Model II-12, and imported into a Geographic Information System (GIS) to permit the visualization of their spatial distribution.

As shown in Table 1, a total of 133 phlebotomine sandflies were captured, including $65(48.9 \%)$ males and 68 (51.1\%) females, from the forest biome $(91.7 \%)$ and peridomestic sites (8.3\%) surveyed. Eight species of the genus Lutzomyia were captured: Lutzomyia (Psathyromyia) pascalei (Coutinho \& Barretto, 1940), Lutzomyia (Psychodopygus) ayrozai (Barretto \& Coutinho, 1940), Lutzomyia (Psychodopygus) hirsuta (Mangabeira, 1942), Lutzomyia (Psychodopygus) matosi (Barretto \& Zago, 1956) Lutzomyia (Psychodopygus) lloydi (Antunes, 1937), Lutzomyia (Evandromyia) edwardsi (Mangabeira, 1941), Lutzomyia (Evandromyia) sallesi (Galvão \& Coutinho, 1939) and Lutzomyia (Lutzomyia) amarali (Barretto \& Coutinho, 1940). The most prevalent species was Lu. pascalei $(42.9 \%)$, followed by Lu. ayrozai $(21.1 \%)$ and Lu. hirsuta (15\%). With the exception of four specimens of the genus Brumptomyia, which were not of interest in this research, all of the captured specimens belonged to the genus Lutzomyia. Furthermore, three specimens of the genus Lutzomyia were damaged and thus could not be identified. These specimens composed $5.3 \%$ of the specimens captured and were found in the São Benedito neighborhood (Table 1).

This study covered the eastern region of the City of Juiz de Fora. Figure 1 shows the spatial distribution of the phlebotomine sandflies. All species found were concentrated in a single area of the region surveyed, within the São Benedito neighborhood. Together, the two São Benedito sites accounted for $94.7 \%$ of the total number of sandflies captured (126 specimens).
No phlebotomine sandflies were captured in seven of the twelve neighborhoods surveyed (Alto Grajaú, Linhares, Parque Burnier/JK, Progresso, Santo Antônio, São Bernardo and São Dimas). Both Lu. lloydi (Nossa Senhora de Lourdes and São Benedito) and Lu. sallesi (Vila Ideal) were found only in peridomestic sites. Lutzomyia amarali, Lu. matosi and $L u$. pascale $i$ were found exclusively in the forest biome (São Benedito). Lutzomyia ayrozai, Lu. edwardsi and Lu. hirsuta were captured from both peridomestic sites and the forest site (São Benedito, Santa Rita and Tiguera, respectively).

This study is the first inventory of phlebotomine sandfly fauna held in Juiz de Fora. The species Lutzomyia intermedia, Lutzomyia migonei and Lutzomyia quinquefer have previously been found in this municipality ${ }^{7,8}$. Therefore, the data obtained in this work add to the available information on the local fauna, identifying eight species of the genus Lutzomyia that have not been previously reported in this city, namely $L u$. amarali, Lu. ayrozai, Lu. edwardsi, Lu. hirsuta, Lu. lloydi, Lu. matosi, $L u$. pascalei and Lu. sallesi. Notably, none of the formerly reported species were found in the present study, possibly because they were captured at different sites within the city or because of possible changes related to biotic and/or abiotic factors. The most prevalent species captured in the present study ( $L u$. pascalei) has been shown to be in a process of geographical expansion. Restricted to the northeastern and southeastern regions of Brazil until recently, it has already been found in southern Brazil ${ }^{9,10}$.

The subgenus Psychodopygus was represented by four species. Some species of this group, i.e., Lu. hirsuta and $L u$. lloydi, have been found to be naturally infected with Leishmania in Minas Gerais ${ }^{11,12}$. Lutzomyia lloydi was found in Juiz de Fora, but at a low frequency.

TABLE 1 - Total numbers and percentages of sandflies captured from thirteen sites in the eastern region of the municipality of Juiz de Fora, State of Minas Gerais, Brazil, from March to September 2012, distributed according to species, sex and habitat.

\begin{tabular}{|c|c|c|c|c|c|c|c|c|c|c|}
\hline \multirow[b]{2}{*}{ Species } & \multicolumn{4}{|c|}{ Peridomestic site } & \multicolumn{4}{|c|}{ Rainforest biome } & & \\
\hline & $\mathrm{n}$ & $\%$ & $\mathrm{n}$ & $\%$ & $\mathrm{n}$ & $\%$ & $\mathrm{n}$ & $\%$ & $\mathrm{n}$ & $\%$ \\
\hline Lutzomyia amarali & - & - & - & - & - & - & 1 & 1.6 & 1 & 0.7 \\
\hline Lutzomyia ayrozai & 1 & 14.3 & 1 & 25.0 & 17 & 29.3 & 9 & 14.1 & 28 & 21.1 \\
\hline Lutzomyia hirsuta & 1 & 14.3 & - & - & 10 & 17.2 & 9 & 14.1 & 20 & 15.0 \\
\hline Lutzomyia lloydi & 5 & 71.4 & - & - & - & - & - & - & 5 & 3.8 \\
\hline Lutzomyia matosi & - & - & - & - & 11 & 18.9 & 9 & 14.1 & 12 & 9.0 \\
\hline Lutzomyia pascalei & - & - & - & - & 17 & 29.3 & 40 & 62.5 & 57 & 42.9 \\
\hline Subtotal & 7 & 5.3 & 4 & 3.0 & 58 & 43.6 & 64 & 48.1 & - & - \\
\hline Total & & & & & & & & & 133 & 100.0 \\
\hline
\end{tabular}




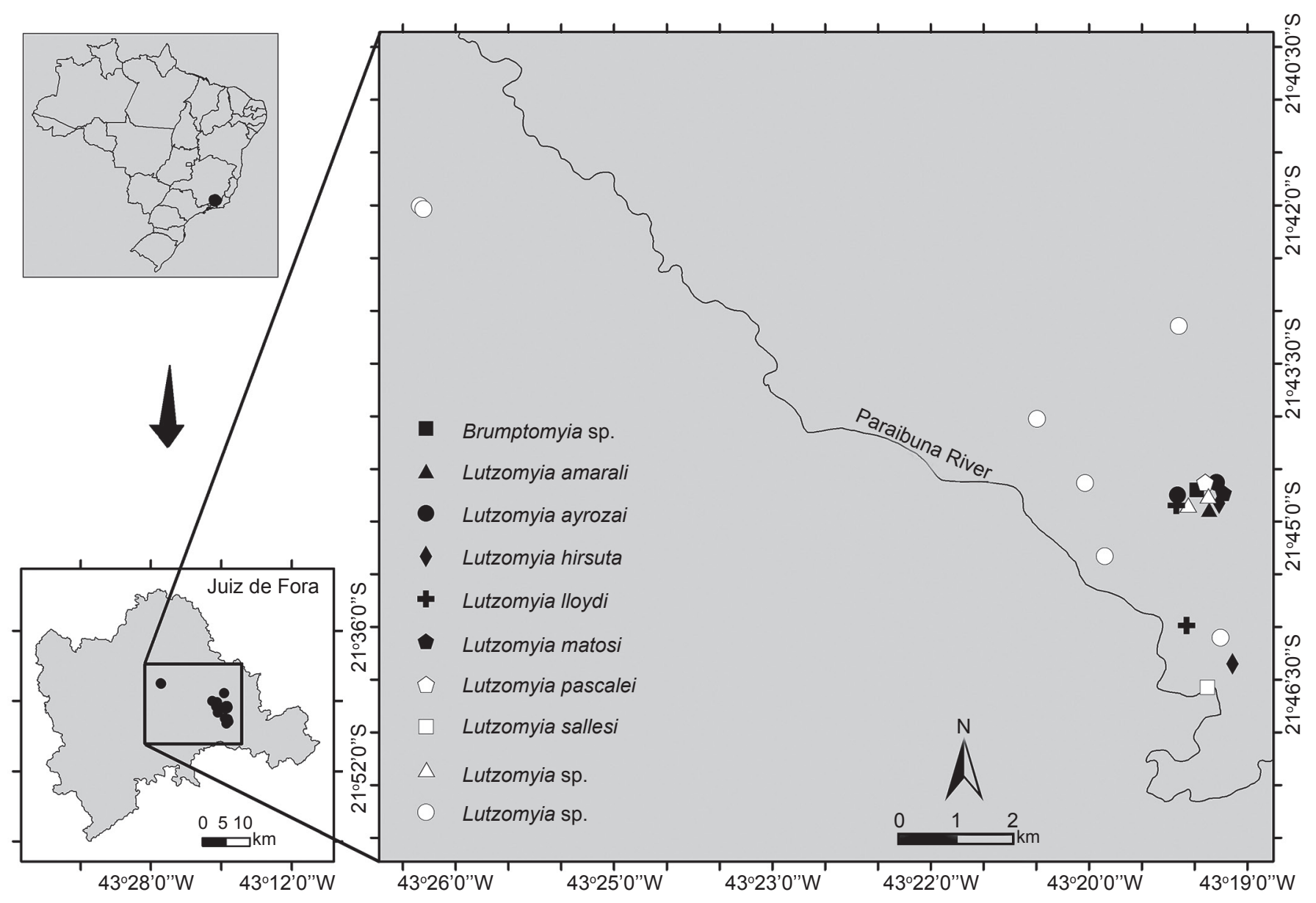

FIGURE 1 - Spatial distribution of sandflies in the municipality of Juiz de Fora, State of Minas Gerais, Brazil. Coverage area of the city showing the sandflies captured in the eastern region from March to September 2012.

In this work, the capture sites were chosen based on reports of the occurrence of asymptomatic dogs seropositive for canine visceral leishmaniasis. However, none of the eight Lutzomyia species found is considered of epidemiological importance in the transmission of this disease. In addition, this research showed that within the study area, a more diverse phlebotomine fauna existed in the natural environment than in those environments subject to anthropic impacts, consistent with the data from the literature ${ }^{1}$. Further surveys will be performed in other areas of the city.

In a recent review, Andrade \& Dantas-Torres showed that at least 93 species included in 16 genera of phlebotomine sandflies identified in Brazil have already been found in the State of Minas Gerais $^{13}$. However, the authors added that many municipalities have not yet been surveyed thoroughly. Thus, our research contributes to the knowledge of the species diversity and spatial locations of the phlebotomine sandfly fauna in Minas Gerais as well as to future studies of the behavior of these insects.

\section{ACKNOWLEDGMENTS}

We are thankful to the superintendent of the Superintendência Regional de Saúde de Juiz de Fora (SRS/JF), Dr. Cláudio Moisés Lacerda Reis; to the coordinator of the Núcleo de Vigilância Epidemiológica, Ambiental e Saúde do Trabalhador, Lourdes Maria Tasca Tavares; to the researchers of the Centro de Pesquisas René Rachou, Rogério Pereira, Juliana Xavier Faustino and Cristiani de Castilho Sanguinette; to Thamiris Mariane de Almeida, Hélio Soares Gomes, Liliane de Souza Vieira, Nívea Maria Farinazzo; and to those responsible for the sites where the traps were placed, for their essential collaboration in this research.

\section{CONFLICT OF INTEREST}

The authors declare that there is no conflict of interest. 


\section{FINANCIAL SUPPORT}

This work was supported by Fundação de Amparo à Pesquisa Científica do Estado de Minas Gerais (FAPEMIG).

\section{REFERENCES}

1. Rangel EF, Lainson R. Apresentação. In: Rangel EF, Lainson R, editors. Flebotomíneos do Brasil. Rio de Janeiro: FIOCRUZ; 2003. p. 13-14.

2. Missawa NA, Lima GBM. Distribuição espacial de Lutzomyia longipalpis (Lutz \& Neiva, 1912) e Lutzomyia cruzi (Mangabeira, 1938) no Estado de Mato Grosso. Rev Soc Bras Med Trop 2006; 39:337-340.

3. Alves WA, Bevilacqua PD. Reflexões sobre a qualidade do diagnóstico da leishmaniose visceral canina em inquéritos epidemiológicos: o caso da epidemia de Belo Horizonte, Minas Gerais, Brasil, 1993-1997. Cad Saude Publica 2004; 20:259-265.

4. JF Minas Website. O portal de turismo de Juiz de Fora e região. Clima [Internet]. 2009; [Cited 2012 July 31]. Available at: http://www.jfminas. com.br/portal/informacao/clima/

5. Pugedo H, Barata RA, França-Silva JC, Silva JC, Dias ES. HP: um modelo apropriado de armadilha luminosa de sucção para captura de pequenos insetos. Rev Soc Bras Med Trop 2005; 38:70-72.

6. Young DG, Duncan MA. Guide to the identification and geographic distribution of Lutzomyia sandflies in Mexico, the West Indies, Central and South America (Diptera: Psychodidae). Mem Amer Entomol Inst 1994; 54:1-881.

7. Andrade Filho JD, Galati EAB, Falcão AL. Nyssomyia intermedia (Lutz \& Neiva, 1912) and Nyssomyia neivai (Pinto, 1926) (Diptera: Psychodidae: Phlebotominae) geographical distribution and epidemiological importance. Mem Inst Oswaldo Cruz 2007; 102:481-487.

8. Martins AV, Williams P, Falcão AL. American sandflies. Academia Brasileira de Ciências. Rio de Janeiro; 1978.

9. Marcondes CB, Santos-Neto LG, Lozovel AL. Ecology of Phlebotomine sandflies (Diptera, Psychodidae) in Brazilian Atlantic Forest. Rev Soc Bras Med Trop 2001; 34:255-260.

10. Eckert J, Souza GD. Flebotomíneos (Diptera: Psychodidae: Phlebotominae) no município de Estrela e primeiro registro de Lutzomyia pascalei (Coutinho \& Barreto) no Rio Grande do Sul. Rev Bras Bioci 2010; 8:399-422.

11. Rangel EF, Ryan L, Lainson R, Shaw JJ. Observations on the sandfly (Diptera: Psychodidade) fauna of Além Paraíba, State of Minas Gerais, Brazil, and the isolation of a parasite of the Leishmania braziliensis complex from Psychodopygus hirsutus hirsutus 1985. Mem Inst Oswaldo Cruz 1985; 80:373-374.

12. Quaresma PF, Carvalho GML, Ramos MCNF, Andrade Filho JD. Natural Leishmania sp. reservoirs and phlebotomine sandfly food source identification in Ibitipoca State Park, Minas Gerais, Brazil. Mem Inst Oswaldo Cruz 2012; 107:480-485.

13. Andrey JA, Dantas-Torres F. Phlebotomine sandflies (Diptera: Psychodidae) of the state of Minas Gerais, Brazil. Neotrop Entomol 2010; 39:115-123. 